\title{
Analytical and Experimental Solution of Vibrations of a System of Bound Bodies
}

Vít Černohlávek ${ }^{1}$, Martin Svoboda ${ }^{1}$, Jan Štěrba ${ }^{1}$, Milan Chalupa ${ }^{1}$, Milan Sapieta ${ }^{2}$

${ }^{1}$ Faculty of Mechanical Engineering, J. E. Purkyně University in Ústí nad Labem, Pasteurova 7, 40096 Ústí nad Labem.E-mail: vit.cernohlavek@ujep.cz,martin.svoboda@ujep.cz, jan.sterba@ujep.cz,milan.chalupa@ujep.cz ${ }^{2}$ Faculty of Mechanical Engineering, Univerzity of Zilina, Unierzitna 1, 01026 Zilina. Slovak Republic. E-mail: milan.sapieta@fstroj.uniza.sk

The article deals with analytical and experimental solution of vertical oscillations of a mechanical system of bound bodies. The content of the article is to perform an analytical solution of the vertical oscillation of a system of bodies using the computer program MathWorks Matlab and MS Excel. Furthermore, an experimental investigation on a laboratory model of a mechanical system of the same parameters was proved. The aim of the work was to compare the analytical solution with the experimental method and to check the accuracy and applicability of analytical methods for the solved mechanical system.

Keywords: vibration, experiment, passenger car, analytical solution, vehicle model

\section{Introduction}

Oscillations can be observed with most technical devices. This oscillation can cause many situations where the service life of the equipment is reduced or the operation of these equipment is accompanied by annoying noise. In the case of means of transport (cars, rail vehicles), limiting the service life and functionality of technical equipment is an unpleasant matter, mainly due to the threat to human health and life. A similar case occurs, for example, in building structures, where there is a risk of the structure collapsing due to repeated vibrations.

The concept of oscillations of mechanical systems can be imagined the process of various physical changes (deviations, velocities, accelerations, forces) in time, which is characterized by increasing or decreasing these values. The total energy of the system takes over the kinetic and potential energy alternately. If the oscillation in the system is to last continuously, the condition is a continuous supply of energy.

Analytical, experimental and numerical methods are used to solve the problem. New numerical methods, along with greater computer performance, help more reliably predict the in-service behavior of machine and system models. The basic condition for success is the construction of a structurally correct computational model of a real mechanical system. The mathematical description of this system is expressed by a mathematical model. The physical parameters of the model can only be determined with limited accuracy. To create mathematical models, it is necessary to identify some parameters based on the results of experiments [1-4].

Often the problem of oscillations is investigated on quarter models, elastically bound, or with dissipative elements, with different numbers of bodies, ie. with models with more degrees of freedom. When applying the quarter model, two axes of symmetry of the system are assumed, which means complete symmetry of the system and its kinematic excitation. The influence of asymmetry of mechanical systems has not been sufficiently investigated so far. In the literature, solutions can be found for spatial half or planar models of mechanical systems, where planar symmetry can be assumed. The complete asymmetry of mechanical systems must therefore be investigated on spatial models [5].

Countless publications and textbooks of technical disciplines are devoted to the basics of the issue of body oscillations, which follow the work of scientists, engineers and authors of basic theoretical works on the oscillation of mechanical systems.

Slavík et al. [6] describe modern methods of mathematical modeling of properties and reactions of dynamically loaded systems of bodies. The authors also describe the method of compiling equations of motion of systems of rigid bodies. There are also documents for dimensioning machines and their strength calculations.

Soukup et al. [7] described a dynamic analysis of a rail vehicle. The article pointed out the possibility of using a newly proposed method that solves the dynamic analysis of a two-axle vehicle. It requires knowledge of the position of the center of gravity and the main central moments of inertia. The article also describes a current solution method for "determining the frequency and damping of the basic types of natural oscillations of the suspension of railway vehicles (for all types of vehicles).

Chlebová [8] in their article focused on a simulation analysis of the controlled oscillation of a vibrating 
device. The article presents a design of a dynamic model of a vibrating mill. The mathematical model of the mechanical system of the mill was solved using Lagrange's equations II. type, on the basis of which a simulation analysis of dynamic equations of motion was performed. The solution describes the deviations of the mechanical system during its oscillating movement in the horizontal and vertical direction.

The publications on which the current professional work on the oscillation of the system of bodies is based include, for example:

Kožešník [9] discusses the theory of vibrations of mechanical systems with special regard to applications in the field of mechanical engineering. It describes both simple systems with one degree of freedom and more complex systems, linear and random vibrations. He pays special attention to the use of Laplace and Fourier integral transforms, matrix and iterative methods, but also various analytical methods.

Brepta et al. [10] provide an overview of mechanical vibration of discrete systems and continua, shock wave propagation, linear and nonlinear systems excited in a deterministic manner or by a random signal. Numerical and analytical methods of solution are also presented.

Zeman, Hlaváć [1] describe in detail the oscillations of linear systems with one or more degrees of freedom and also explain the basics of random oscillations of one-dimensional continua and nonlinear systems with one degree of freedom.

Stejskal, Okrouhlík [11] provide a brief overview of basic principles and computational procedures that use problems about oscillations of mechanical systems. The book deals mainly with real systems. Discrete systems and systems with continuously distributed parameters are explained. Great attention is paid to the use of the finite element method. The examples solved here either illustrate the phenomenon discussed or are an example from technical practice.

Considerable attention is paid to the issue of vibration of a system of bodies. The authors focus mainly

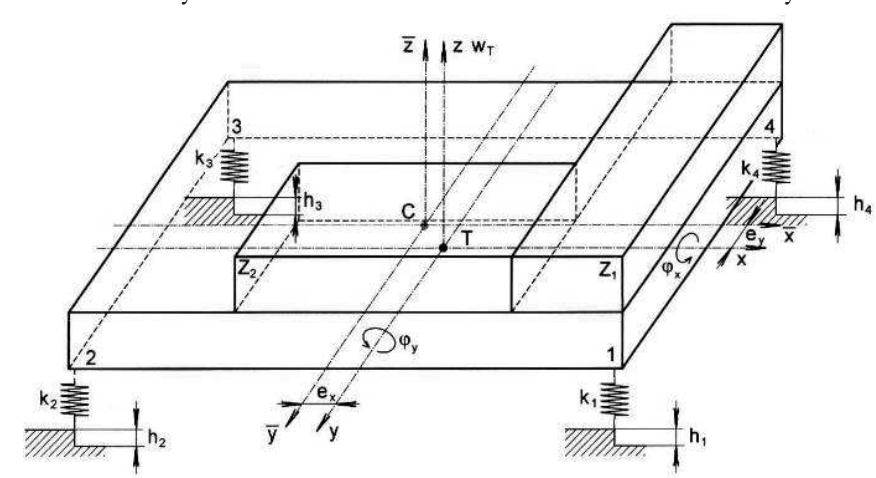

Fig. 1 Example of asymmetrical arrangement of balances on a model board (3D model and floor plan)

The analytical solution of the vertical oscillation of the system will be performed in the computer program Matlab and also in the program MS Excel. In MS

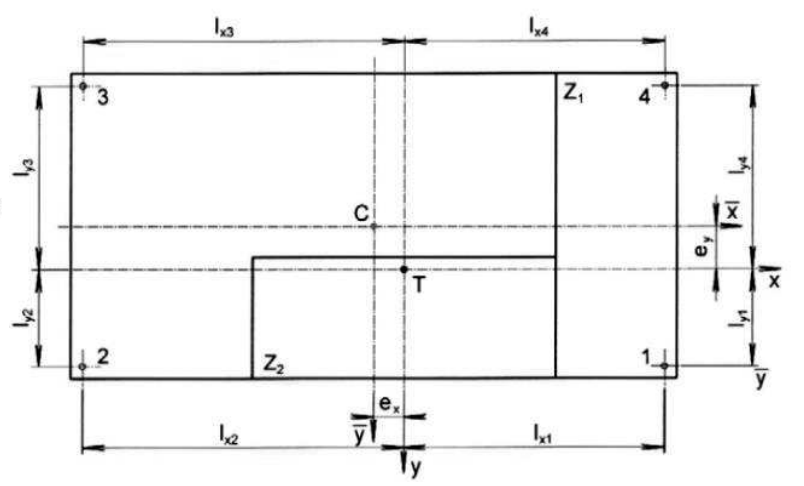

on symmetric systems, information about asymmetric systems is absent.

\section{Mechanical system model}

The mechanical system has entered parameters according to the already assembled laboratory model. It is a steel plate, which is mounted on four coil springs of known stiffness. Two balances (equal to a quarter of the weight of the plate) are placed on the steel plate. This makes it possible to achieve an asymmetrical arrangement of the system. The plate is excited by a spring jump (one or more) of $5 \mathrm{~mm}$. Inductive position sensors measure the vertical displacements of the specified points (centers of spring mounting).

In the case of a symmetric system, the center of gravity $\mathrm{T}$ lies at the intersection of the axes of geometric symmetry, which define the coordinate system $(x$, $y, z)$. External forces and moments act on the body. For the case of a symmetric system, it holds that $C \equiv$ $T\left(C\right.$ - geometric center, $T$ - center of gravity), $e_{x}=0$, $e_{y}=0$. The main axes of inertia are identical with the axes of geometric symmetry.

In an asymmetrical assembly of the system, the center of gravity $T$ is deviated from the geometric center of the system $C$ by the values $e_{x}$ and $e_{y}$ (see Fig. 1).

The vertical oscillation will then be performed using the analytical method in Matlab and MS Excel. The results will be compared with experiments that will be performed on a laboratory model of a mechanical system.

The aim of the work is the analysis of the vertical oscillation of the mechanical system. The work will be performed analytical and experimental investigation of the vertical oscillation of the system at different kinematic excitation.

The experiments will be performed on a laboratory model of a mechanical system, which is located in the laboratories of the Institute of Machinery and Power Engineering FME JEPU.

Excel, the analytical solution will be considered without damping. An analysis will be performed in the Matlab program, including the damping coefficient of 
the springs.

The main goal of the work is to compare the experimental results with analytical and thus verify the accuracy and applicability of the analytical method for the solved mechanical system.

\section{Location variants}

For the case of a symmetrical system, the arrangement of the balancers on the plate according to Fig. 2 was chosen. Both balancers were located in the middle of the plate. In this case, the center of gravity is identical with the geometric center of the system $(C \equiv T)$.

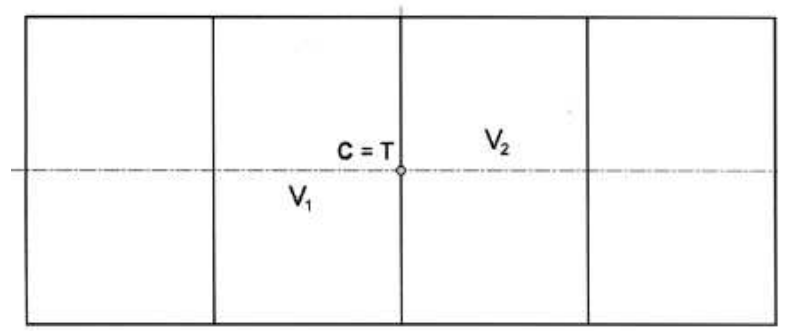

Fig. 2 Symmetrical arrangement of the system

For the asymmetrical arrangement of the system, the location of both balances on the right side of the base plate was chosen (see Fig. 3). In this case, the center of gravity is deflected $e_{x}$ in the longitudinal direction $(C \neq T)$.

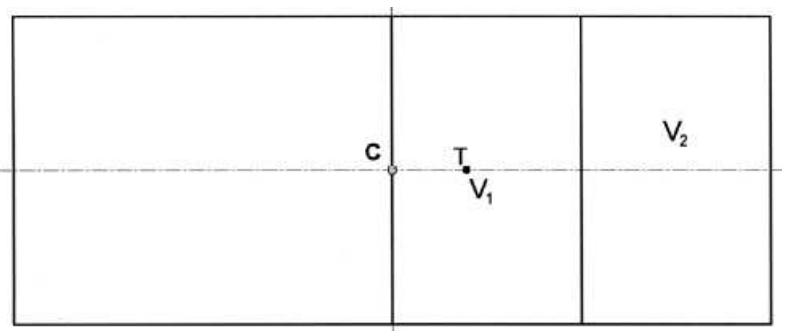

Fig. 3 Asymmetrical arrangement of the system

The springs were numbered 1 to 4 - according to Fig. 1. In Tab. 1 we can observe six proposed variants

$$
\frac{d}{d t}\left(\frac{\partial E_{k}}{\partial \dot{q}_{j}}\right)-\frac{\partial E_{k}}{\partial q_{j}}+\frac{\partial E_{p}}{\partial q_{j}}+\frac{\partial R_{d}}{\partial \dot{q}_{j}}=Q_{j}, \quad \text { for } j=1,2, \ldots p
$$

where $p$ is the number of degrees of freedom of the system, $R_{d}$ is the Rayleigh function of the dissipated energy. In this case, the equation of motion applies to our solved model (not considered damping) in the form

$$
M \ddot{q}_{j}+K q_{j}=F_{j}(t) \quad \text { for } j=1,2,3
$$

Where generalized coordinates

$$
q_{1}(t)=\left[w_{T}(t), \varphi_{x}(t), \varphi_{y}(t)\right]^{T}
$$

of kinematic excitation. The jump of all four springs at one time (variant F) corresponds to the symmetrical excitation of the system. Other variants (A to E) correspond to asymmetrical excitation (jump of one to three springs in different combinations).

Tab. 1 Used variants of kinematic excitation

\begin{tabular}{|c|c|}
\hline $\begin{array}{c}\text { Asymmetric excitation vari- } \\
\text { ant }\end{array}$ & Jumping springs \\
\hline \hline $\mathrm{A}$ & 3 \\
\hline $\mathrm{B}$ & 2,4 \\
\hline $\mathrm{C}$ & 3,4 \\
\hline $\mathrm{D}$ & 2,3 \\
\hline $\mathrm{E}$ & $1,2,3$ \\
\hline \hline $\begin{array}{c}\text { Symmetric excitation vari- } \\
\text { ant }\end{array}$ & Jumping springs \\
\hline $\mathrm{F}$ & $1,2,3,4$ \\
\hline \hline
\end{tabular}

\section{Analytical solution of the vertical oscilla- tion of the model without damping}

For a simple case of vibration of the model without damping, a plate without balances was solved, the following parameters were chosen

Board weight $m=20 \mathrm{~kg}$

Moments of inertia $J_{x}=0,351 \mathrm{kgm}^{2} J_{y}=0,905 \mathrm{kgm}^{2}$

Angle of rotation of the axes of inertia $\delta=0 \mathrm{rad}$

Spring stiffness constant $K=9700 \mathrm{Nm}_{2}$

Distances $l_{x}=0,3335 \mathrm{~m} \quad l_{y}=0,134 \mathrm{~m}$

Eccentricity of the center of gravity $e_{x}=0 e_{y}=0$

Eccentricity of the center of gravity - asymmetric plate $e_{x}=0,1 m e_{y}=0,1 \mathrm{~m}$

Jump height $h=5 \mathrm{~mm}$

Furthermore $M$ is a matrix of mass, $K$ is a matrix of stiffness, $F(t)$ is a vector of force excitation effects.

The equations of motion for the spatial model were obtained using Lagrange equations of the second kind:

In a symmetric model and symmetric kinematic excitation, the differential equations in the system are independent of each other, for $j=1$ the differential equation is inhomogeneous and for $j=2$ and 3 the equations are homogeneous. This reduces the system to one equation, its solution

$$
q_{1}(t)=w_{T}(t)=\frac{\mathbf{1}}{\Omega_{\mathbf{1}}} \int_{\mathbf{0}}^{\boldsymbol{t}} \boldsymbol{F}_{\mathbf{1}}(\boldsymbol{\tau}) \sin \Omega_{\mathbf{1}}(\boldsymbol{t}-\boldsymbol{\tau}) \boldsymbol{d} \boldsymbol{\tau}
$$

where for $k_{m}=k$ and $h_{m}=b$; and by $F_{1}=\frac{4 k}{m} h(t)$ and $\varphi_{x}(t)=0, \varphi_{y}(t)=0$. For jump $h(t)=-1$ is 


$$
w_{T}(t)=-\frac{4 k}{\Omega_{1}}\left(1-\cos \Omega_{1} t\right)
$$

With a symmetric arrangement of the model and asymmetric kinematic excitation or with an asymmet- ric model and with symmetric excitation and asymmetric model and asymmetric kinematic excitation, the solution of the equation for $q_{1}(t)=w_{T}(t), q_{2}(t)=\varphi_{x}(t)$, $q_{3}(t)=\varphi_{y}(t)$.

$$
q_{j}(t)=\sum_{i=1}^{3}(-1)^{j+1} \sum_{k=1}^{3} \frac{L_{\eta k}}{\Omega_{k}} \int_{0}^{t} F_{t}(\tau) \sin \Omega_{k}(t-\tau) d \tau, \text { for } j=1,2,3
$$

The courses of vertical displacements are given by the relations: Vertical displacement of the general point of a symmetric model

$$
w_{i}(t)=w_{T}(t)+x_{i} \varphi_{y}(t)-x_{i} \varphi_{x}(t),
$$

Vertical displacement of plate points 1 to 4 (asymmetrical systems)

$$
\begin{aligned}
& w_{1}(t)=w_{T}(t)+\left(l_{x}-e_{x}\right) \varphi_{y}(t)-\left(l_{x}-e_{y}\right) \varphi_{x}(t) \\
& w_{2}(t)=w_{T}(t)-\left(l_{x}-e_{x}\right) \varphi_{y}(t)-\left(l_{x}-e_{y}\right) \varphi_{x}(t) \\
& w_{3}(t)=w_{T}(t)-\left(l_{x}-e_{x}\right) \varphi_{y}(t)+\left(l_{x}-e_{y}\right) \varphi_{x}(t) \\
& w_{4}(t)=w_{T}(t)+\left(l_{x}-e_{x}\right) \varphi_{y}(t)+\left(l_{x}-e_{y}\right) \varphi_{x}(t)
\end{aligned}
$$

\section{Analytical solution of the vertical oscilla- tion of the model with damping}

The equations of motion were compiled for the Matlab computer program, in which graphical results of the vertical oscillation of the mechanical system for the proposed variants of various kinematic excitations were then obtained. In the upper part of the picture you can always see the whole course of changes in the position of individual points (centers of springs) after the excitation of the system until its attenuation. At the bottom of the image, we can observe the course of the fifth to eighth seconds, thanks to which the individual shapes of oscillations at the respective points can be seen.

In Fig. 4 we can observe the jump of all four springs in a symmetrically arranged system. All points of the plate (center of gravity, centers of spring mounting) have the same shape and course, the curves merge into one.

The measured data were processed in the LabVIEW program and then transferred to the MS Excel program for creating graphs. For a symmetrical system, the arrangement of weights on the board was chosen according to Fig. 10. The distribution of weights for an asymmetrical system is shown in Fig. 11.

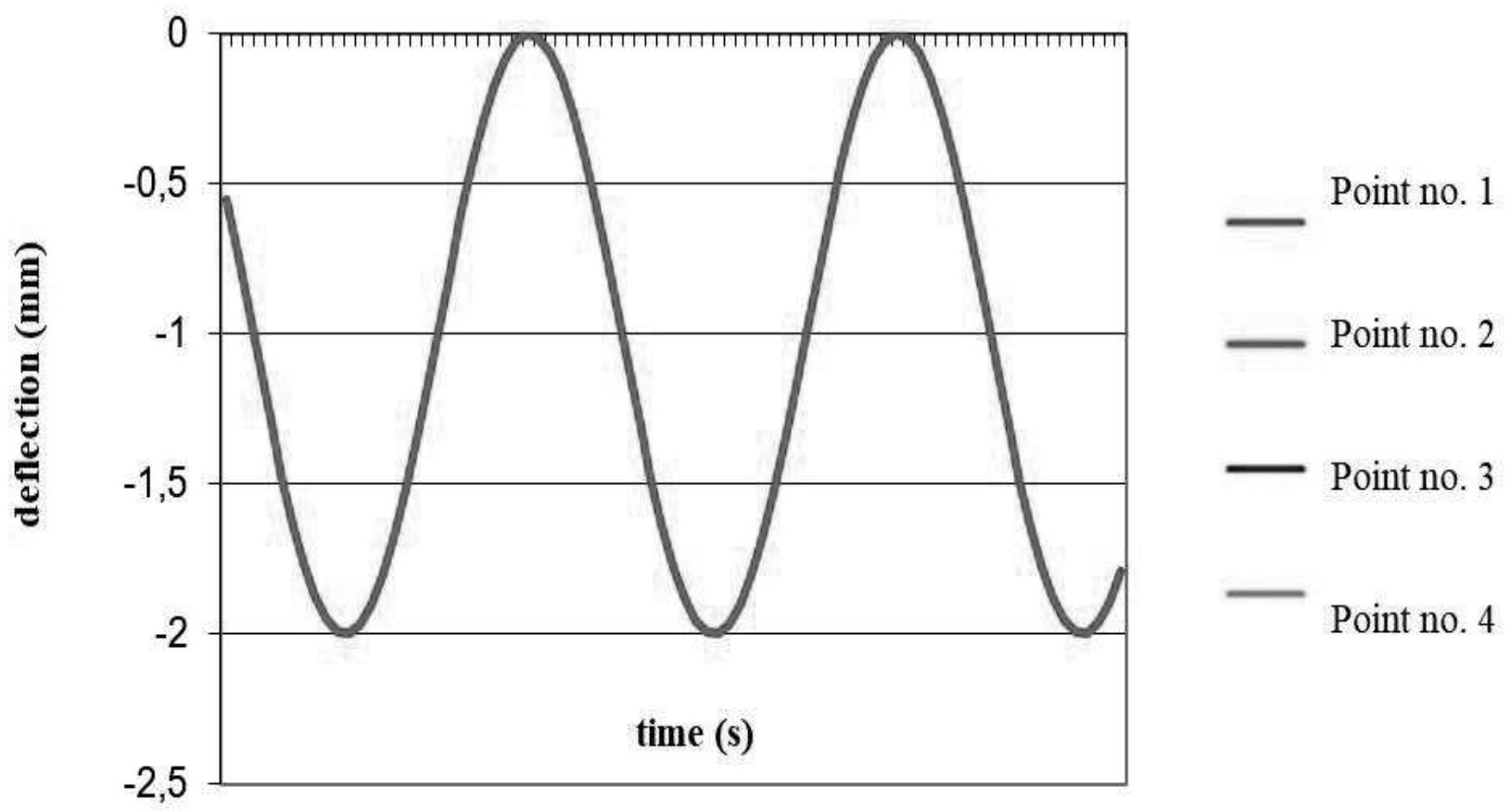

Fig. 4 Symmetric system symmetrically excited 
Symmetrical model, asymmetrical excitation - relative vertical deflectio of attachment points: wheel jump 3

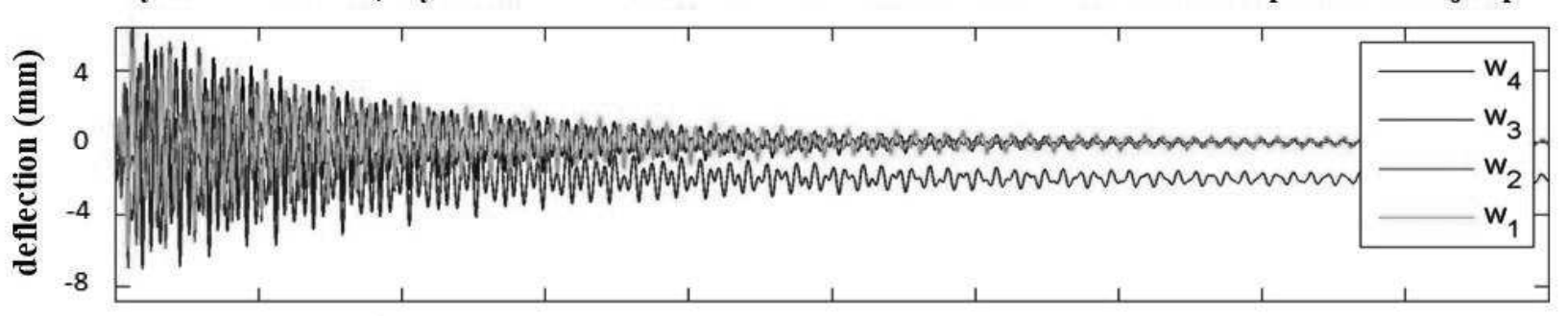

time (s)

Course of shifts of points $1,2,3$ and 4 . Time from $5 \mathrm{~s}$ to $8 \mathrm{~s}$.

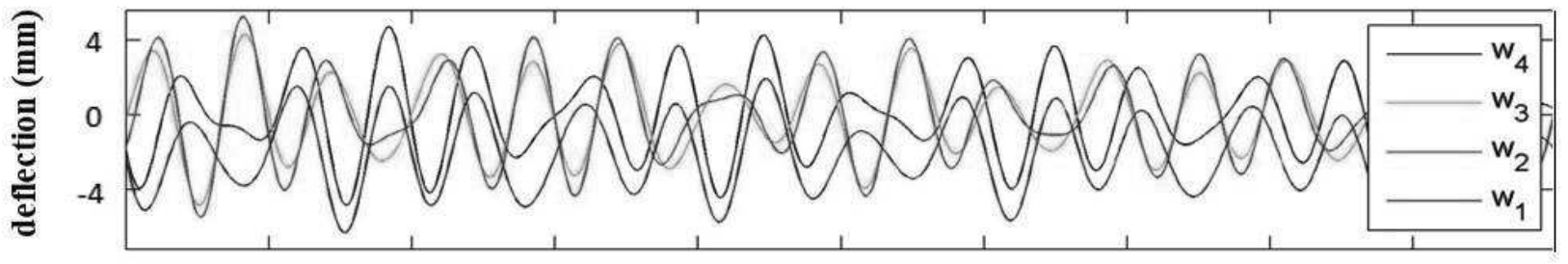

Fig. 5 Symmetrical system, asymmetrical excitation (spring jump 3)

Symmetrical model, asymmetrical excitation - relative vertical deviations of attachment points: jump 2 and 3

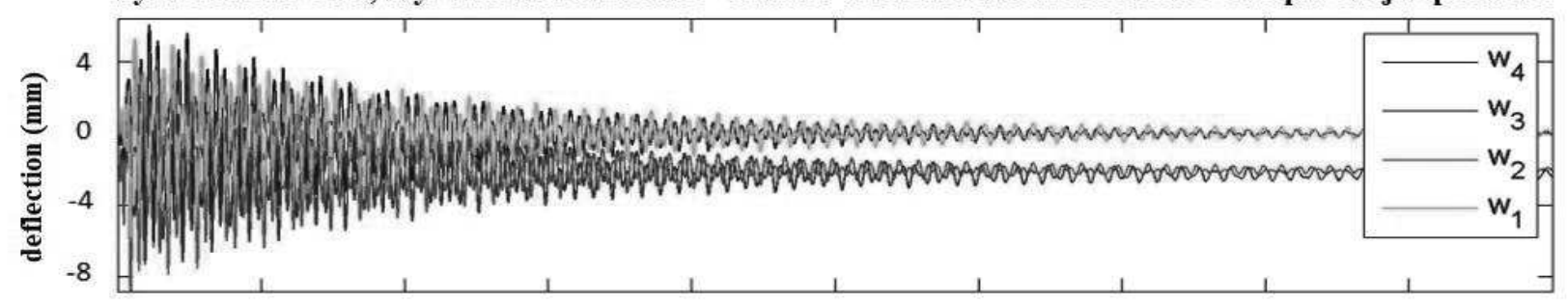

time (s)

Course of shifts of points $1,2,3$ and 4 . Time 5 s to 8 s.

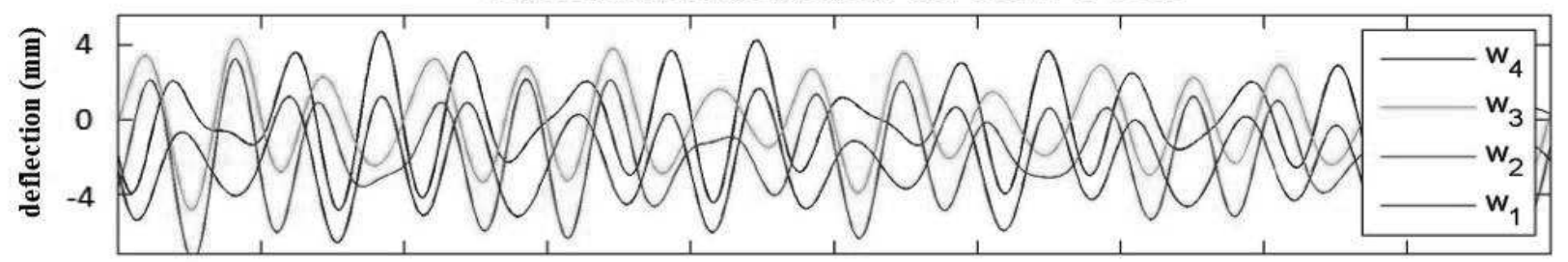

Fig. 6 Symmetrical system, asymmetrical excitation (spring jump 2 and 3)

Symmetrical model, asymmetrical excitation - relative vertical deviations of attachment points: jump 2 and 4

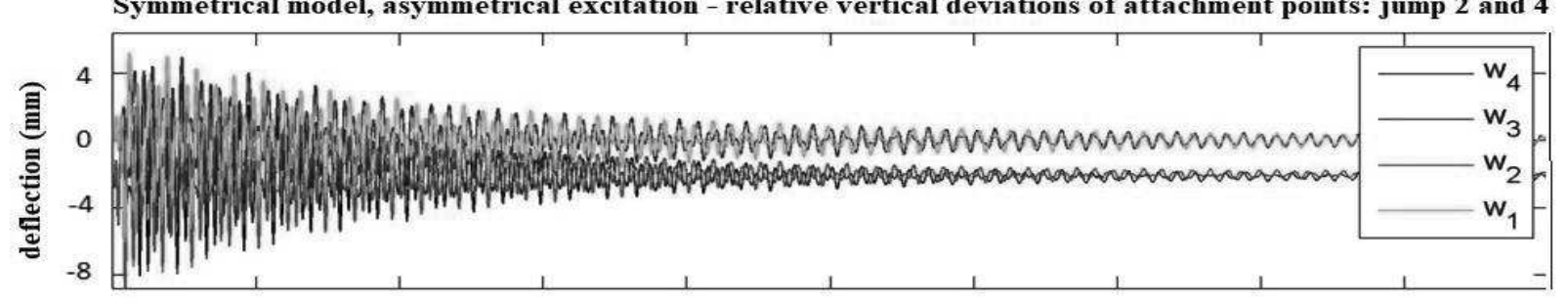

time (s)

The course of the shift of points $1,2,3$ and 4 . Time from $5 \mathrm{~s}$ to $8 \mathrm{~s}$.

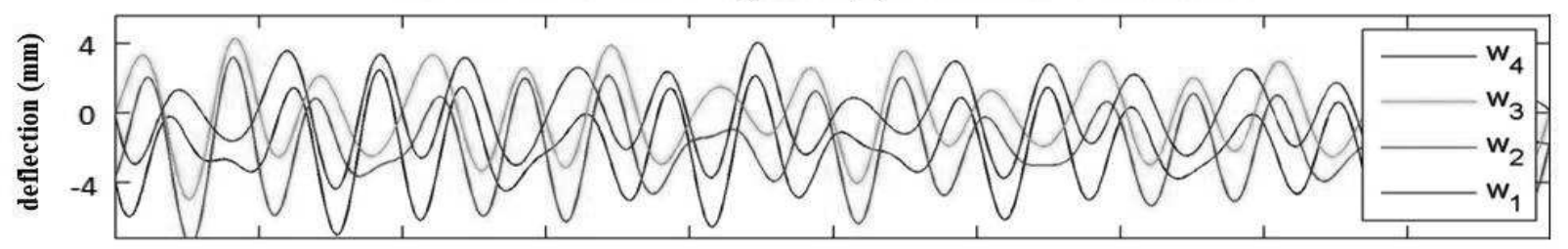

Fig. 7 Symmetrical system, asymmetrical excitation (spring jump 2 and 4) 
Symmetrical model, asymmetrical excitation - relative vertical deviations of attachment points: jump 3 and 4

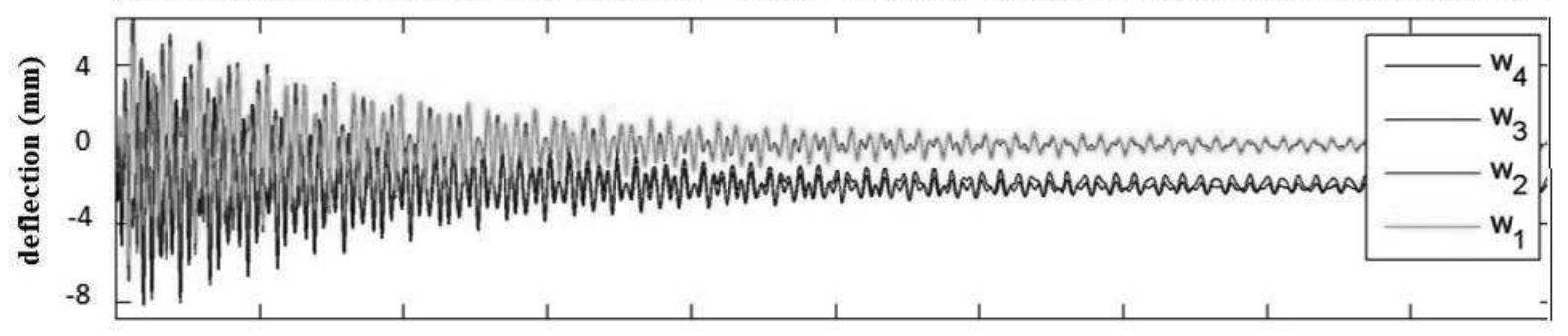

time (s)

The course of the shift of points $1,2,3$ and 4 . Time from $5 \mathrm{~s}$ to $8 \mathrm{~s}$.

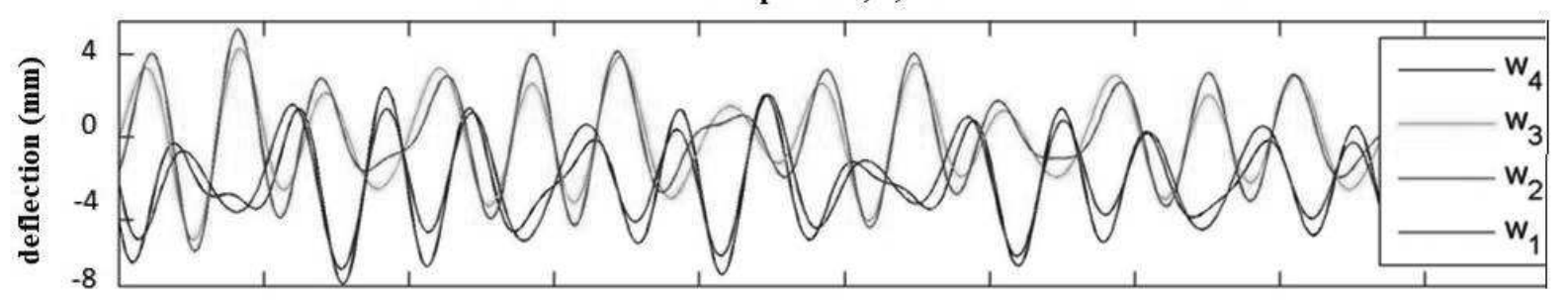

Fig. 8 Symmetrical system, asymmetrical excitation (spring jump 3 and 4)

Symmetrical model, asymmetrical excitation - relative vertical deviations of attachment points: jump 2, 3 and 4

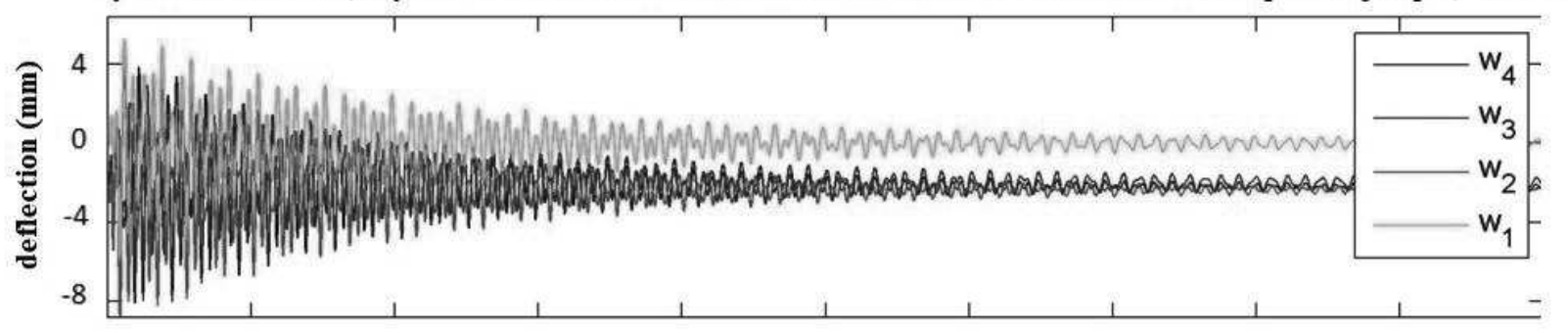

time (s)

Course of shifts of points $1,2,3$ and 4 . Time 5 s to $8 \mathrm{~s}$.

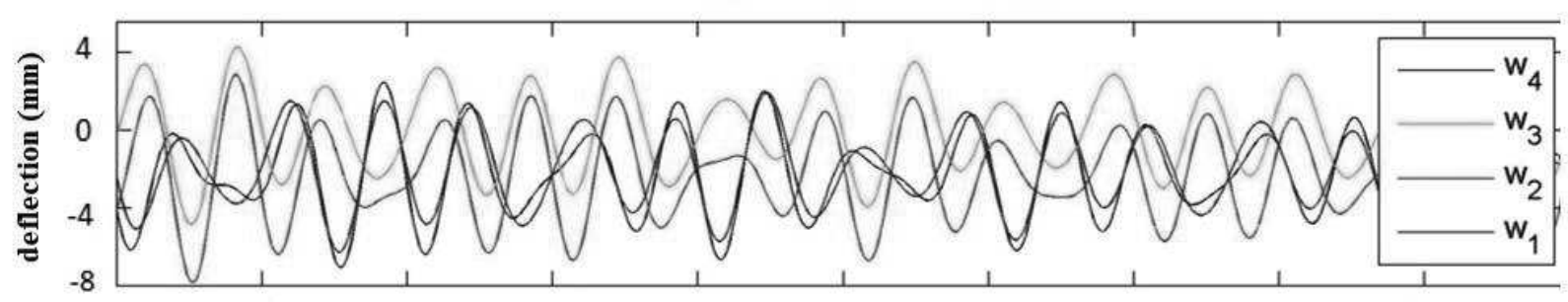

Fig. 9 Symmetrical system, asymmetrical excitation (spring jump 2, 3 and 4)

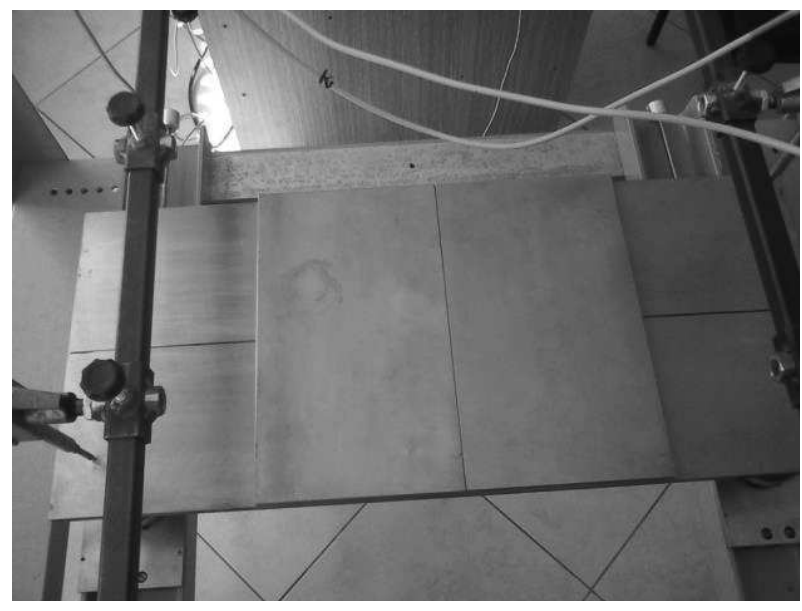

Fig. 10 Arrangement of balances for a symmetrical system

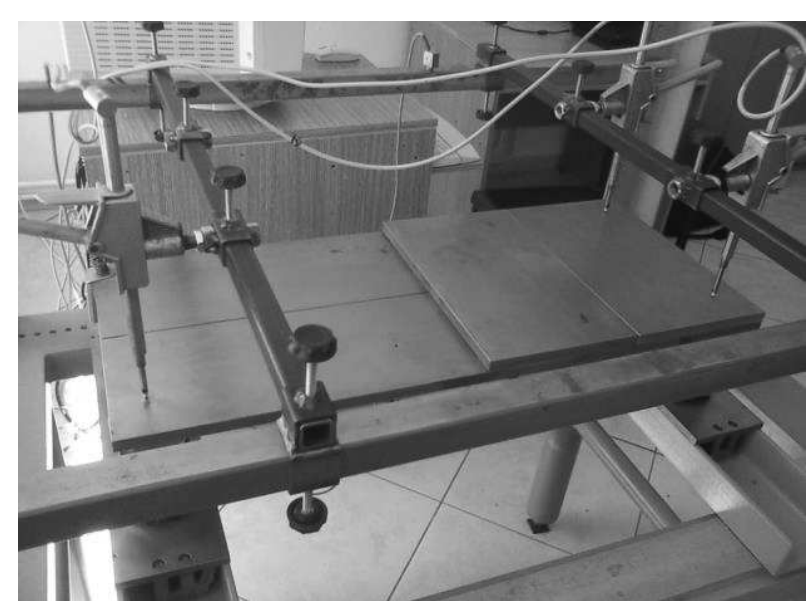

Fig. 11 Arrangement of balances for asymmetric system 
In the following figures we see a graphical representation of the course of changes in the deviations of individual points of the plate in symmetrical and asymmetrical systems with different methods of kinematic excitation. In the upper part of the figure, the total course of oscillations from the moment of deflection of the system from the equilibrium position to the complete stabilization of the plate is recorded. The lower part of the figure always shows the shape of the oscillations in a period of one to two seconds.

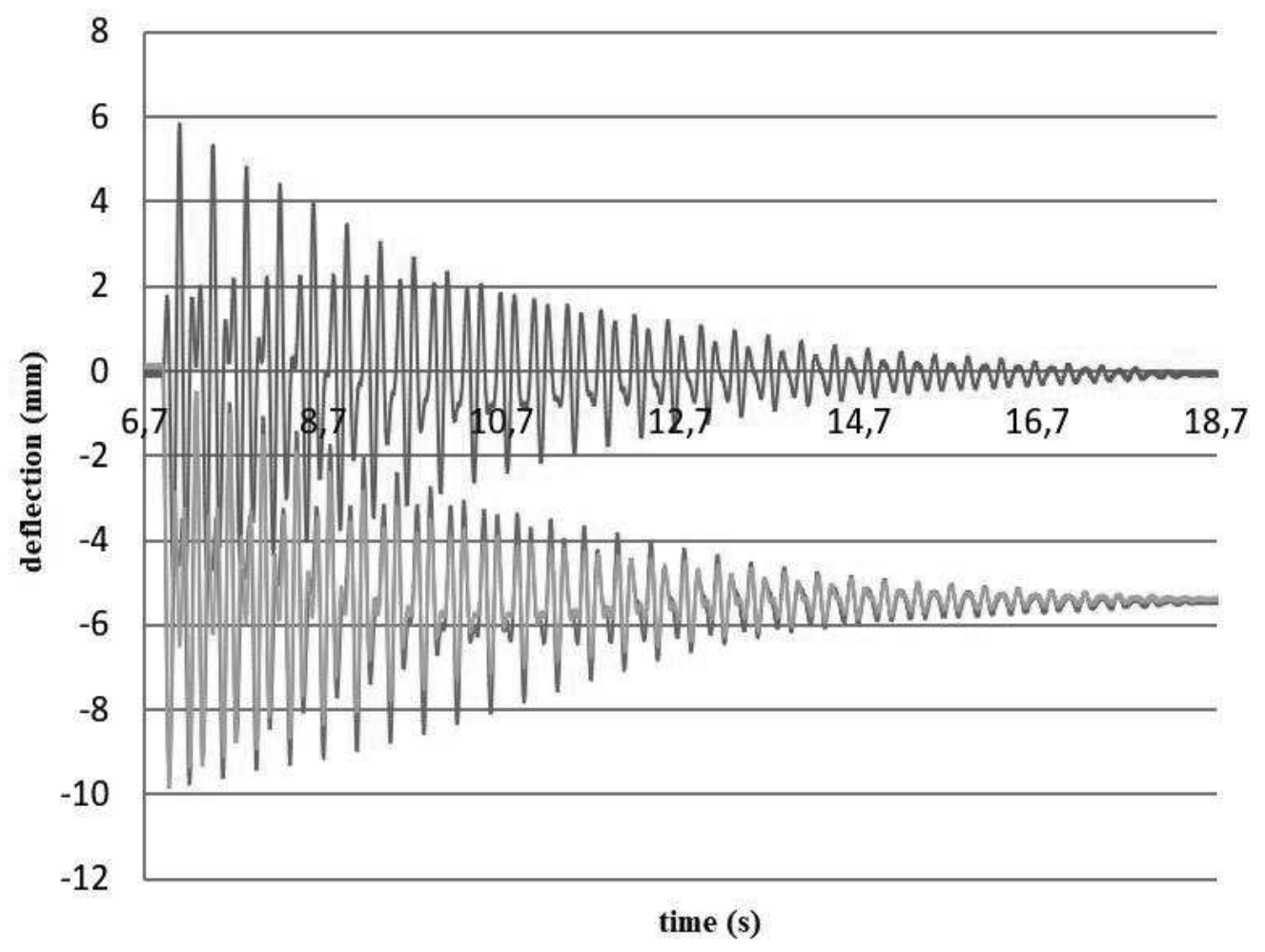

Sensor 3

Sensor 2

Sensor 1

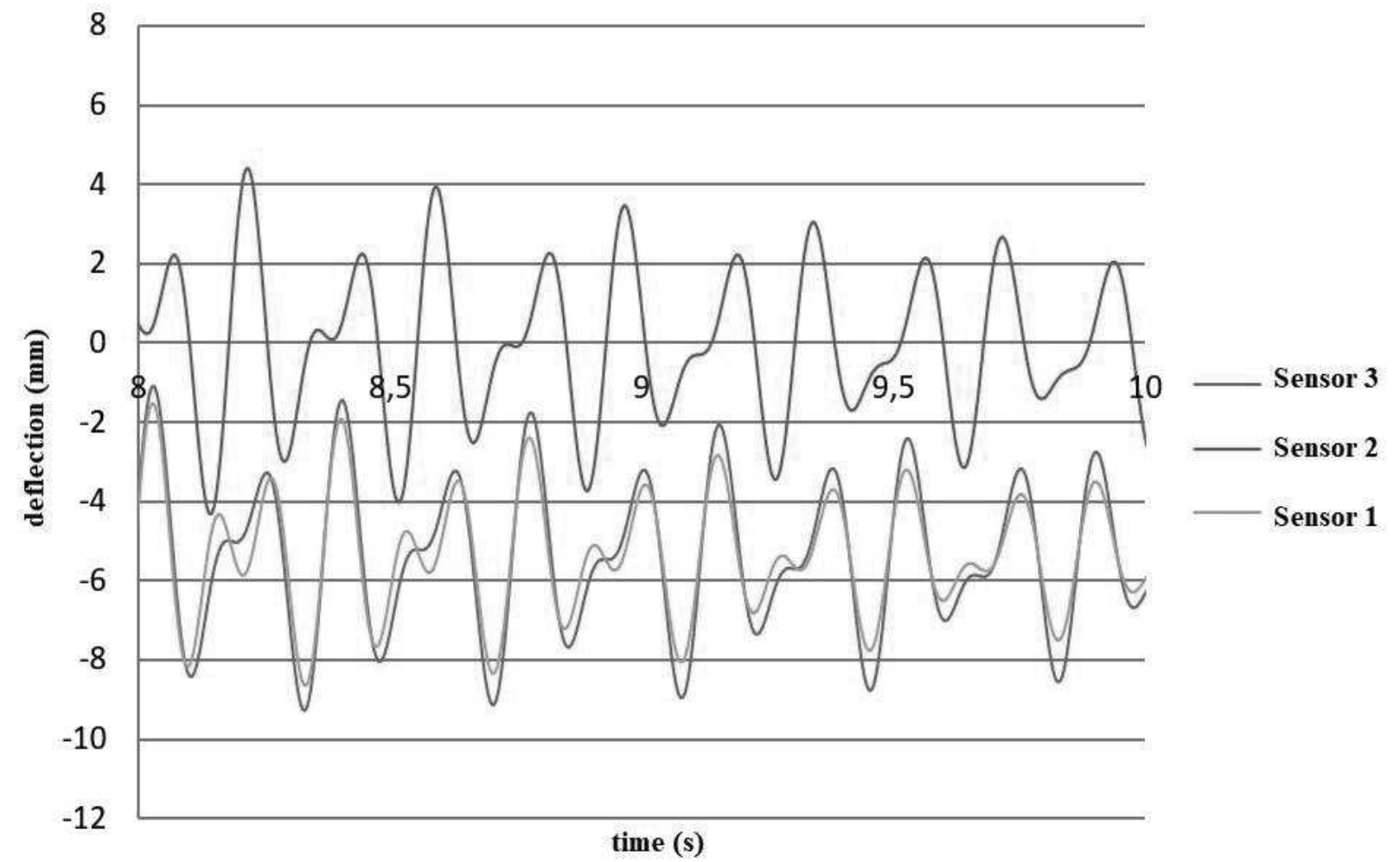

Fig. 12 Symmetrical system - spring jump 3, 4 
In Fig. 12 we can observe the course of displacements of the measured points of a symmetrically arranged system during its asymmetrical excitation (spring jump 3 and 4). Regular repetition of oscillations of individual points can be seen at the bottom of the picture. After the jump of the front part of the side of the mechanical system, the system will be attenuated in less than 12 seconds.

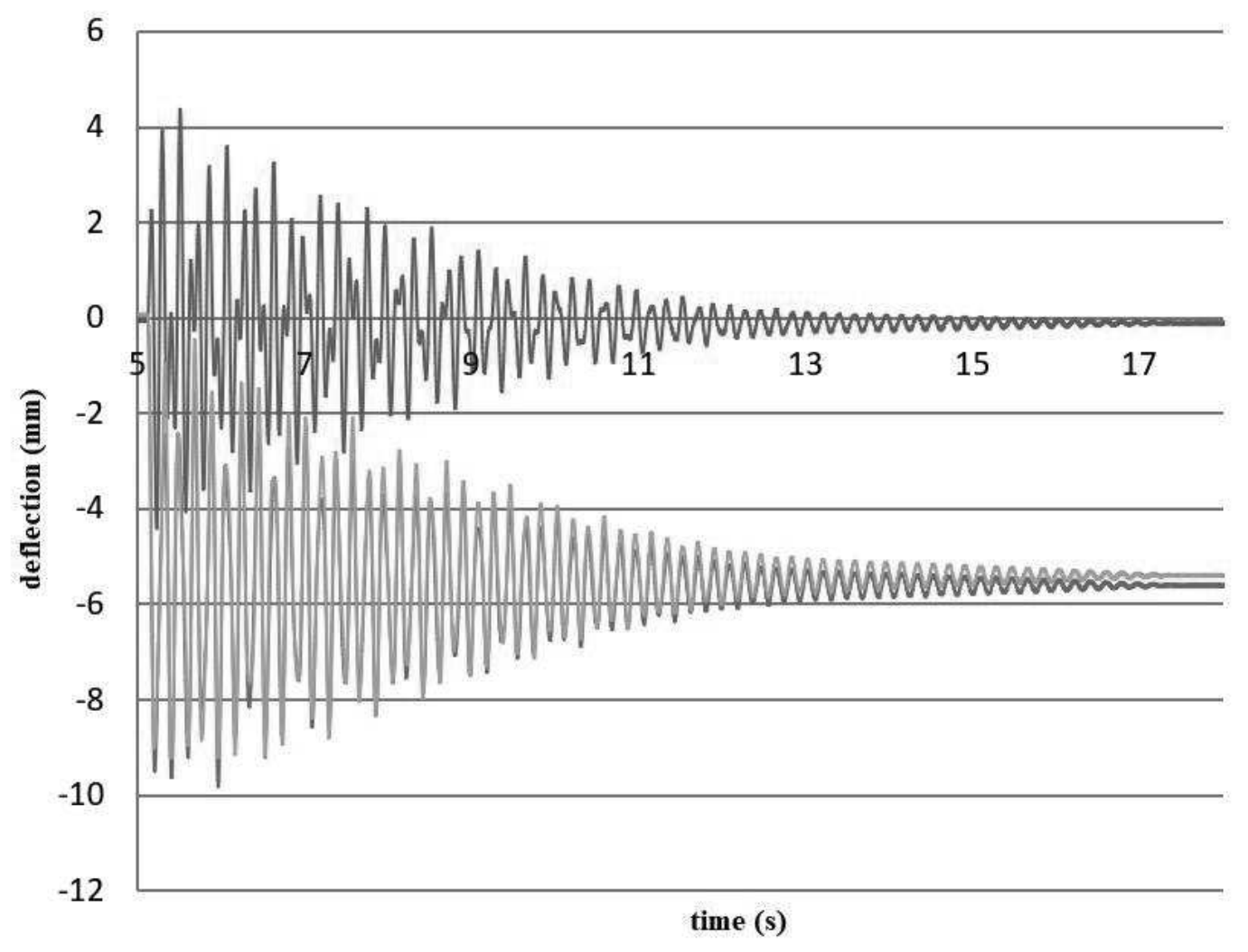

Sensor 3

Sensor 2

Sensor 1

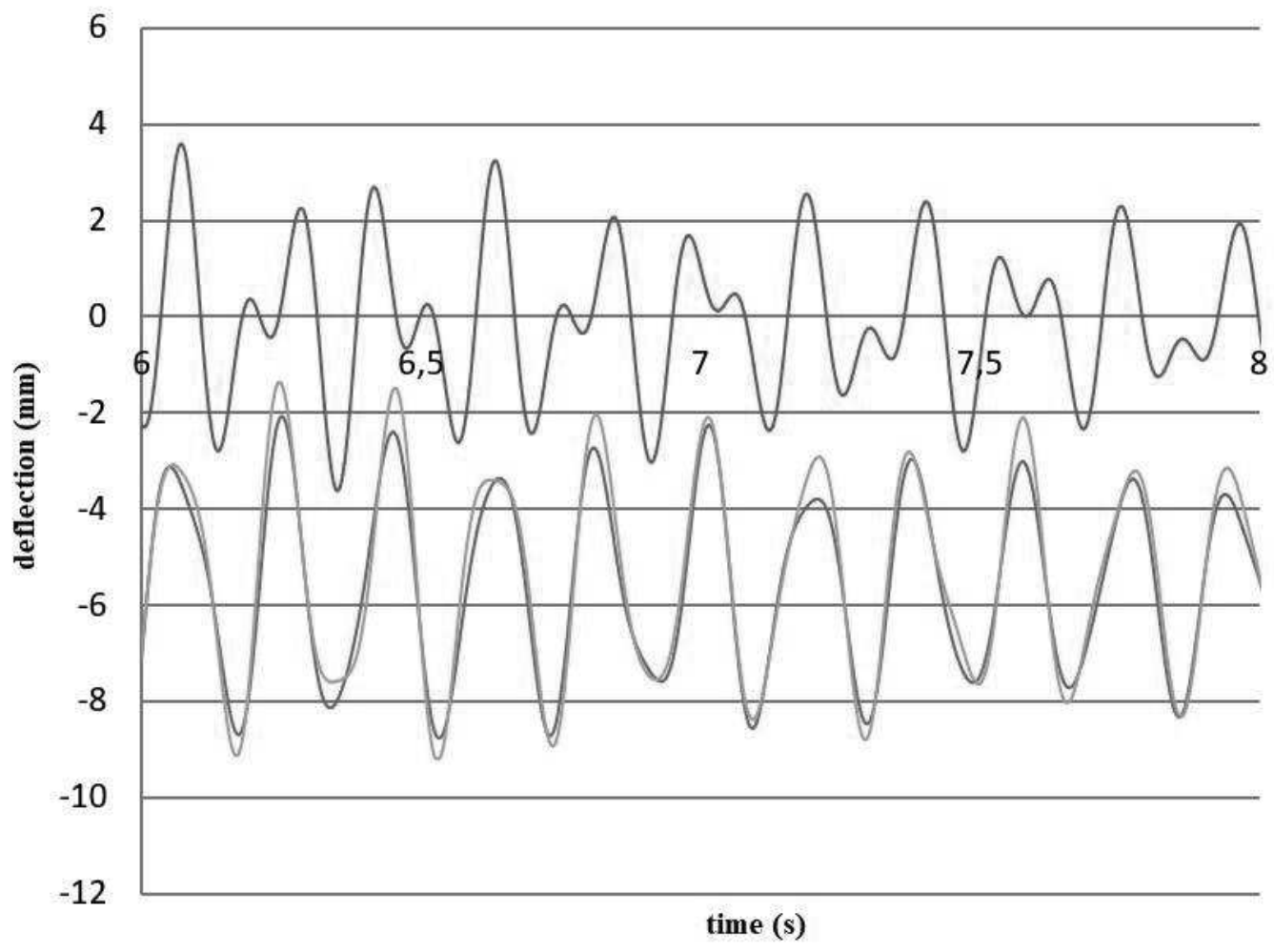

Sensor 3

Sensor 2

Sensor 1

Fig. 13 Asymmetrical system - spring jump 3, 4 
The work derived the equations of motion of the solved mechanical system. One variant of symmetrical and one variant of asymmetrical arrangement of the system (different placement of two balances on the motherboard) was chosen to determine the similarity of the results of the analytical solution and the experiment. Variants of different kinematic excitation of the system were also chosen. Excitation was performed by spring jumps. A total of six variants of different jumps were proposed. Symmetrical excitation of the system was performed by jumping all four springs at the same time. The other five excitation variants were asymmetric, where one or more springs jumped in different combinations.

The calculation was also performed in the MS Excel program, which, however, did not include system damping. A symmetric system was solved in the MS Excel Program (all cases of excitation).

The experimental investigation was performed on a laboratory model of a mechanical system. The same storage and excitation cases were investigated. Position changes were measured by three inductive displacement sensors. A virtual tool for measuring and processing data has been created in LabVIEW. Graphic processing was performed in MS Excel.

Due to the complexity of determining the spring damping coefficient, it was not possible to compare the time length of complete damping of the system after its excitation. To determine the attenuation time of symmetrically and asymmetrically arranged systems by means of analytical investigation, it is necessary to determine the attenuation coefficient of springs. This is possible by calculation (logarithmic decrement) using the measured data in the experimental investigation.

The result of the work was that the time course of oscillations in the analytical and experimental survey was the same (95.5\% agreement). This makes it possible to use the derived equations of the analytical survey to determine the oscillation of individual parts of the mechanical system (simplified vehicle model).

\section{Acknowledgment}

The article was created with the contribution of SGS grant support - Jan Evangelista Purkyně University in Ústí nad Labem UJEP-SGS-202048-001-2 and by grant UJEP-IGA-TC-2019-48-042.

\section{References}

[1] ZEMAN, V., HLAVÁČ, Z. (1999). Vibration of mechanical systems. ZČU in Pilsen. ISBN 807082-563-4
[2] SVOBODA, M., SOUKUP, J.: The Influence of Geometry, Manufacturing Asymmetry and Asymmetric Excitation on Vertical Vibration of a Mechanical System. Applied Mechanics and Materials, vol. 302 (2013), p. 429-434. Trans Tech Publications, Switzerland, 2013, ISSN 1660-9336

[3] SVOBODA, M., SOUKUP, J.: Verification of Numeric Solution by Experiment for Examination Vertical Oscillation of a Mechanical System. In: Manufacturing Technology, Vol. 13, No. 4 (2013) pp 559-563, ISSN: 1213-2489

[4] KLIMENDA F., SOUKUP J., SKOČILASOVÁ B., SKOČILAS J.: Vertical vibration of the vehicle when crossing over transverse speed bumps. In: Manufacturing Technology. Vol. 20, No. 1 (2020) pp 55-59, ISSN: 1213-2489, DOI: $10.21062 / \mathrm{mft} .2020 .020$

[5] SAPIETA, M., ŠULKA, P., SVOBODA, M.: Using a numerical model to verification of thermoelastic analysis of flat specimen, In: Manufacturing Technology, Vol. 18, No. 3 (2018) pp 482486, ISSN: 1213-2489, DOI: 10.21062/ujep/125.2018/a/12132489/MT/18/3/482

[6] SLAVÍK J., STEJSKAL V., ZEMAN V. (1997). Fundamentals of machine dynamics, ČVUT, Prague. ISBN 80-01-01622-6, 319 s.

[7] SOUKUP, J., SKOČILAS, J., SKOČILASOVÁ, B. (2008). Experimental determination of natural frequencies and stiffness of resilience of a resiliently mounted body, application to road and rail vehicles, Acta Mechanica Slovana, Slovak republic

[8] CHLEBOVÁ, Z. (2008). Experimental identification of unfavorable modes of operation of the vibrating device, Acta Mechanica Slovana, Slovak Republic

[9] KOŽEŠNíK, J. (1979). Vibration of mechanical systems, Academia, Prague

[10] BREPTA, R., PƯST, L., TUREK, F. (1994). Mechanical vibration - Technical guide 71, Sobotáles, Prague, ISBN 80-901684-8-5

[11] STEJSKAL, V., BAUMA, V., VAMPOLA, T. (2003). Vibration of mechanical systems, ČVUT, Prague, ISBN 80-01-02752-X 